\title{
Special issue on clubroot and blackleg diseases of brassicas - Foreword
}

\author{
Elke Diederichsen - Geoffrey R. Dixon - Ann-Charlotte Wallenhammar • \\ Dilantha Fernando $\cdot$ Marie-Hélène Balesdent
}

Published online: 23 May 2016

C) Koninklijke Nederlandse Planteziektenkundige Vereniging 2016

The two plant pathogens Leptosphaeria maculans (anamorph Phoma lingam), causal agent of blackleg disease, and Plasmodiophora brassicae Wor., causal agent of clubroot disease, are leading to significant yield and quality losses in both agricultural and horticultural brassica crops worldwide. The increasing economic and social importance of brassica crops, which are hosts to both pathogens, has enhanced and financed international

\section{E. Diederichsen $(\bowtie)$ \\ Institut für Biologie - Angewandte Genetik, Freie Universität Berlin, Albrecht-Thaer-Weg 6, D-14195 Berlin, Germany e-mail: elked@zedat.fu-berlin.de}

\section{G. R. Dixon}

GreenGeneInternational, Helenton Mote, Symington By-Ayr, Kilmarnock, Ayrshire KA1 5PP, UK

\section{G. R. Dixon}

Department of Agriculture, Policy \& Development, University of Reading, Reading, UK

\section{A.-C. Wallenhammar}

Rural Economy and Agricultural Society| HS Konsult AB, Box 271, SE /01 45 Örebro, Sweden

\section{A.-C. Wallenhammar}

Department of Soil and Environment, Swedish University of Agricultural Sciences, Skara, Sweden

\section{Fernando}

Deprtmant of Plant Science, University of Manitoba, Winnipeg, MB R3T 2N2, Canada

M.-H. Balesdent

UMR BIOGER, INRA, AgroParisTech, Université Paris-Saclay, 78850 Thiverval-Grignon, France research collaborations over the past two decades. Both are aggressive and race-forming pathogens that have thrived because of intensive cropping of oilseed rape (B. napus). Clubroot, in particular, has caused increasing devastation in high value horticultural crops such as cauliflower or broccoli.

Extensive broad-acre field crops are frequently grown in short rotations, which include only a few non-host crops such as cereals or legumes. Farming systems increasingly include contract machinery cultivating many hectares of land in short periods with only very limited opportunities for cleaning. Both farming practices increase the incidences and spread of these diseases. High value horticultural brassicas have long been hosts to both pathogens. Brassica crops are more and more valued as contributing significantly to human health and wellbeing. Consequently, research interest in both pathogens has grown rapidly and our present knowledge has benefitted from several research initiatives.

This Special Issue of the European Journal of Plant Pathology is the third such publication produced in the last 7 years regarding clubroot, and is supplemented by papers on blackleg. It highlights significant advances in the understanding of both host-pathogen interactions at the populations and molecular level. Genomic studies of the brassica hosts and on the two pathogens have revealed their biology and the manner in which they interact. The drive for environmentally sustainable control has created opportunities for breeding, biological control, and agronomical measures which employ intelligent systems of integrated control. Many of the 
contributed papers result from workshops that were held during the European Foundation for Plant Pathology conference in Cracow, Poland, in 2014, and a clubroot meeting at Chungnam University, Daejeon, South Korea, in 2015. Both meetings had strong international participation and the contributions of this Special Issue reflect the major progress in research on the two pathogens. We gratefully acknowledge the support of the Editor-in-Chief and all those who contributed to the quality of the manuscripts by their peer reviews. 